\title{
A transcriptome profile in gallbladder cancer based on annotation analysis of microarray studies
}

\author{
CHUNLIN GE $^{1^{*}}$, XUAN ZHU $^{1,2^{*}}$, XING NIU $^{3}$, BINGYE ZHANG $^{1}$ and LIJIE CHEN ${ }^{3}$ \\ ${ }^{1}$ Department of General Surgery, The First Affiliated Hospital of China Medical University, Shenyang, \\ Liaoning 110001; ${ }^{2}$ Department of General Surgery, Anshan Hospital, The First Affiliated Hospital of \\ China Medical University, Anshan, Liaoning 114011; ${ }^{3}$ Department of Second Clinical College, \\ Shengjing Hospital Affiliated to China Medical University, Shenyang, Liaoning 110004, P.R. China
}

Received September 29, 2019; Accepted June 25, 2020

DOI: $10.3892 / \mathrm{mmr} .2020 .11663$

\begin{abstract}
The purpose of the present study was to identify aberrantly expressed genes for gallbladder cancer based on the annotation analysis of microarray studies and to explore their potential functions. Differential gene expression was investigated in cholesterol polyps, gallbladder adenoma and gallbladdercancer using microarrays. Subsequently,microarray results were comprehensively analyzed. Gene Ontology (GO) and Kyoto Encyclopedia of Genes and Genomes (KEGG) analyses were performed to determine the affected biological processes or pathways. Differentially expressed genes (DEGs) of cholesterol polyps, gallbladder adenoma and gallbladder cancer were identified. Following comprehensive analysis, 14 genes were found to be differentially expressed in the gallbladder wall of both gallbladder cancer and gallbladder adenoma. The 20 most significantly upregulated genes were only upregulated in the gallbladder wall of gallbladder cancer, but not in the gallbladder wall of cholesterol polyps and gallbladder adenoma. In addition, 182 DEGs were upregulated in the gallbladder wall of gallbladder adenoma compared with the gallbladder wall of cholesterol polyps. A total of 20 most significant DEGs were found in both the tumor and gallbladder wall of gallbladder cancer. In addition, the most significant DEGs that were identified were only upregulated in the tumor of gallbladder cancer. GO and KEGG analysis
\end{abstract}

Correspondence to: Dr Chunlin Ge, Department of General Surgery, The First Affiliated Hospital of China Medical University, 155 Nanjing North Street, Heping, Shenyang, Liaoning 110001, P.R. China

E-mail: gechunlin126@126.com

*Contributed equally

Abbreviations: DEGs, differentially expressed genes; GO, Gene Ontology; KEGG, Kyoto Encyclopedia of Genes and Genomes; aRNA, amplified RNA; FC, fold-change

Key words: gallbladder diseases, gallbladder cancer, cholesterol polyps, gallbladder adenoma, biomarkers indicated that the aforementioned DEGs could participate in numerous biological processes or pathways associated with the development of gallbladder cancer. The present findings will help improve the current understanding of tumorigenesis and the development of gallbladder cancer.

\section{Introduction}

Gallbladder cancer is the most common malignant tumor of the biliary tract and is the third most common gastrointestinal malignancy worldwide (1). Due to the vague clinical symptoms and signs of gallbladder cancer, most patients are diagnosed at an advanced stage (2). Since the etiology and pathogenesis of gallbladder cancer are still unclear, it is essential to research the molecular mechanism of the disease and explore novel potential biomarkers that may assist early diagnosis and treatment.

Gallbladder adenoma is a rare disease and rarely malignant, but transformation may occur (3). Previous evidence has proposed that adenomas are the premalignant lesions of gallbladder cancer $(3,4)$. However, the genetic evidence is still poorly defined (5). Due to the poor prognosis of gallbladder cancer, it is crucial to distinguish benign and malignant gallbladder adenoma (6). There is a need for accurate diagnostic methods to distinguish between benign and malignant diseases. Currently, the size and number of gallbladder polyps, along with patient age, are typically used to assist with distinguishing benign and malignant diseases (7). For example, previous research has found that conjugated bile acids (glycochenodeoxycholic and taurochenodeoxycholic) could be identified as possible biomarkers for cholesterol polyps and adenomatous polyps, and the gallbladder bile acids glycochenodeoxycholic acid and taurochenodeoxycholic acid are highly expressed in cholesterol polyps (8). For patients with gallbladder carcinoma, compared with healthy individuals and patients with cholesterol polyps, serum vascular endothelial growth factors (SVEGF)-C are closely related with lymph node metastasis, distant metastasis and stage, in addition, SVEGF-D has a positive relationship with the tumor depth, lymph, distant metastasis and stage that could represent available biomarkers for the diagnosis of gallbladder carcinoma (6). 
The present study aimed to comprehensively analyze a transcriptome profile and identify DEGs in gallbladder cancer based on annotation analysis of microarray studies.

\section{Materials and methods}

Patients and tissue samples. Gallbladder stones (two men and one woman; age range, 60-62 years), gallbladder adenoma (two men and one woman; age range, 60-62 years) and gallbladder carcinoma (two men and one woman; age range, 60-63 years) tissues $(n=3$ each) were obtained from the Department of Pancreaticobiliary Surgery, the First Affiliated Hospital of China Medical University between September 2018 and December 2019. All cases were reviewed by two or more independent pathologists. No patients received radiation or chemotherapy before surgery. During the surgery, fresh tumor tissues or gallbladder wall tissues were collected in the operating room and immediately frozen in liquid nitrogen within $15 \mathrm{~min}$ and then stored in RNA Fixer reagent (Thermo Fisher Scientific, Inc.) at $-80^{\circ} \mathrm{C}$ for total RNA extraction. The present study was approved by the Ethics Committee of The First Affiliated Hospital of China Medical University (2018075). All patients who participated in the study signed written informed consent.

RNA extraction and transcript analysis. RNA extraction was performed using an RNeasy kit (Qiagen, Inc.) according to the manufacturer's protocol. Total RNA was quantified using a NanoDrop ND-2000 spectrophotometer (Thermo Fisher Scientific, Inc.) and the RNA integrity was assessed with an Agilent Bioanalyzer 2100 (Agilent Technologies, GmbH). Total RNA samples were analyzed on the Agilent Bioanalyzer 2100 and amplified RNA (aRNA) was prepared using the GeneChip 3'IVT Express kit (Affymetrix; Thermo Fisher Scientific, Inc.). Briefly, cDNA was synthesized by reverse transcription, and a double-stranded DNA template was then obtained by second-strand synthesis. Subsequently, an aRNA labeled with biotin was inverted in vitro utilizing GeneChip 3'IVT Express kit (Affymetrix; Thermo Fisher Scientific, Inc.) at $40^{\circ} \mathrm{C}$ for $16 \mathrm{~h}$ and stored at $4^{\circ} \mathrm{C}$. The aRNA was purified, fragmented and hybridized with the chip probe (Beckman Coulter, Inc.). Following hybridization, the chip was automatically washed using a GeneChip Hybridization Wash and Stain kit (Affymetrix; Thermo Fisher Scientific, Inc.) and dyed using GeneChip Fluidics Station 450 instrument (Affymetrix; Thermo Fisher Scientific, Inc.). Finally, it was scanned to obtain the image and the Affymetrix microarray data using a GeneChip Scanner 3000 (Affymetrix; Thermo Fisher Scientific, Inc.).

To obtain the raw data, the Feature Extraction function in GeneSpring (version 10.5.1.1; Agilent Technologies, GmbH) was utilized to analyze the array image. Briefly, the raw data were normalized with the quantile algorithm. In the experiment, probe groups in the lowest $20 \%$ of the signal strength in the two sample groups were filtered as background noise. The coefficient of variation of the probe group was calculated in the sample group, and the probe group with a coefficient of variation $>25 \%$ in both groups were also filtered out. Finally, DEG transcripts were identified.

To explore DEGs in different gallbladder diseases, further analysis was conducted, as shown in Table I. In the present study, gallstones served as normal samples compared with cholesterol polyps, gallbladder adenoma and gallbladder cancer.

Differential expression analysis. In the present study, linear models for microarray data (version 3.44.3; Bioconductor) were performed based on empirical Bayesian distribution to calculate the P-value (9). The screening criteria for DEGs was as follows: |Fold change (FC) $\mid>1.5$ and $\mathrm{P}$-value $<0.05$. To probe out DEGs in cholesterol polyps, gallbladder adenoma and gallbladder cancer, differential expression analyses including scatter plot analysis, volcano plot analysis and hierarchical clustering analysis were performed using GraphPad Prism (version 7.0; GraphPad Software, Inc.).

Comparative analysis. To explore differentially expressed genes between different diseases a comparative analysis was undertaken, as shown in Table II and Fig. 1. In group II, the gallbladder wall of gallbladder adenoma and gallbladder wall of gallbladder stones were compared. In group III, the gallbladder wall of gallbladder cancer and gallbladder wall of gallbladder stone were compared. In group IV, comparative analysis was performed between gallbladder wall of gallbladder adenoma and gallbladder wall of cholesterol polyps. For group V, comparative analysis between gallbladder wall of gallbladder cancer and gallbladder wall of gallbladder adenoma was presented.

Functional enrichment analysis. To explore the biological processes or pathways involved in DEGs, Gene Ontology (GO; http://geneontology.org/) and Kyoto Encyclopedia of Genes and Genomes (KEGG; https://www.kegg.jp/kegg/) pathway enrichment analyses were performed $(10,11)$. GO terms include 'biological process' (BP), 'molecular function' (MF) and 'cellular component' (CC).

Validation of the differential expression and prognostic value of key genes using gene expression profiling interactive analysis (GEPIA). Key genes were verified by GEPIA (http://gepia.cancer-pku.cn/) in The Cancer Genome Atlas (https://www.cancer.gov/about-nci/organization/ccg/research/ structural-genomics/tcga) and Genotype-Tissue Expression dataset (GTEx; http://commonfund.nih.gov/GTEx/) (12). Differential expression and overall survival (OS) analyses were performed.

Reverse transcription-quantitative PCR (RT-qPCR) assay. A total of 10 pairs of gallbladder cancer tissues and normal tissues (five men and five woman; age range, 55-65 years) were collected from the Department of Pancreaticobiliary Surgery, the First Affiliated Hospital of China Medical University between September 2018 and December 2019. All patients signed written informed consent. Total RNA was extracted from tissues using TRIzol ${ }^{\circledR}$ reagent (Invitrogen; Thermo Fisher Scientific, Inc.). According to the manufacturer's instructions, reverse transcription was performed using a TaqMan Real-Time PCR kit (Applied Biosystems; Thermo Fisher Scientific, Inc.). RT-qPCR was run on a CFX96 Real-Time PCR detection system (Bio-Rad Laboratories, Inc.). The following primer pairs were used for the qPCR: HLA class II histocompatibility 
Table I. Six groups for differential expression analysis via microarray analysis.

\begin{tabular}{llll}
\hline Groups & Tissue type & Number of samples & Comparison \\
\hline Group I & Gallbladder wall & 3 & Cholesterol polyps vs. gallbladder stones \\
Group II & Gallbladder wall & 3 & Gallbladder adenoma vs. gallbladder stones \\
Group III & Gallbladder wall & 3 & Gallbladder cancer vs. gallbladder stones \\
Group IV & Gallbladder wall & 3 & Gallbladder adenoma vs. cholesterol polyps \\
Group V & Gallbladder wall & 3 & Gallbladder cancer vs. gallbladder adenoma \\
Group VI & Tumor tissue & 3 & Gallbladder cancer vs. gallbladder adenoma \\
\hline
\end{tabular}

Table II. Comprehensive analysis of DEGs in the six groups.

\begin{tabular}{|c|c|c|c|c|c|c|}
\hline $\begin{array}{l}\text { Comparative } \\
\text { groups }\end{array}$ & $\begin{array}{l}\text { Gallbladder } \\
\text { wall of } \\
\text { gallstone }\end{array}$ & $\begin{array}{l}\text { Cholesterol } \\
\text { polyps } \\
\text { (gallbladder } \\
\text { wall) }\end{array}$ & $\begin{array}{c}\text { Gallbladder } \\
\text { adenoma } \\
\text { (gallbladder } \\
\text { wall) }\end{array}$ & $\begin{array}{l}\text { Gallbladder } \\
\text { cancer } \\
\text { (gallbladder } \\
\text { wall) }\end{array}$ & $\begin{array}{l}\text { Gallbladder } \\
\text { adenoma } \\
\text { (tumor wall) }\end{array}$ & $\begin{array}{c}\text { Gallbladder } \\
\text { cancer } \\
\text { (tumor wall) }\end{array}$ \\
\hline I & 0 & $\sqrt{ }$ & & & & \\
\hline II & 0 & & $\sqrt{ }$ & & & \\
\hline III & ○ & & & $\sqrt{ }$ & & \\
\hline IV & & O & $\sqrt{ }$ & & & \\
\hline V & & & ० & $\sqrt{ }$ & & \\
\hline VI & & & & & O & $\sqrt{ }$ \\
\hline \multicolumn{7}{|l|}{ A } \\
\hline $\mathrm{a}=\mathrm{I} \cap \mathrm{II} \cap \mathrm{III}$ & & $\sqrt{ }$ & $\sqrt{ }$ & $\sqrt{ }$ & & \\
\hline $\mathrm{b}=\mathrm{II} \cap \mathrm{III}-\mathrm{a}$ & & & $\sqrt{ }$ & $\sqrt{ }$ & & \\
\hline$c=I I-b-I \cap I I$ & & & $\sqrt{ }$ & & & \\
\hline $\mathrm{d}=\mathrm{III}-\mathrm{b}-\mathrm{I} \cap \mathrm{III}$ & & & & $\sqrt{ }$ & & \\
\hline $\mathrm{B}=\mathrm{IV}$ & & & $\sqrt{ }$ & & & \\
\hline $\mathrm{C}=\mathrm{V} \cap \mathrm{VI}$ & & & & $\sqrt{ }$ & & $\sqrt{ }$ \\
\hline $\mathrm{D}=\mathrm{VI}-\mathrm{V} \cap \mathrm{VI}$ & & & & & & $\sqrt{ }$ \\
\hline
\end{tabular}

$\cap$ represents the common DEGs between two groups, $\sqrt{ }$ and $\circ$ represent different samples (gallbladder wall of gallstone, gallbladder wall of cholesterol polyps, gallbladder wall of gallbladder adenoma and tumor wall of gallbladder adenoma) used for intersection. DEGs, differentially expressed genes.

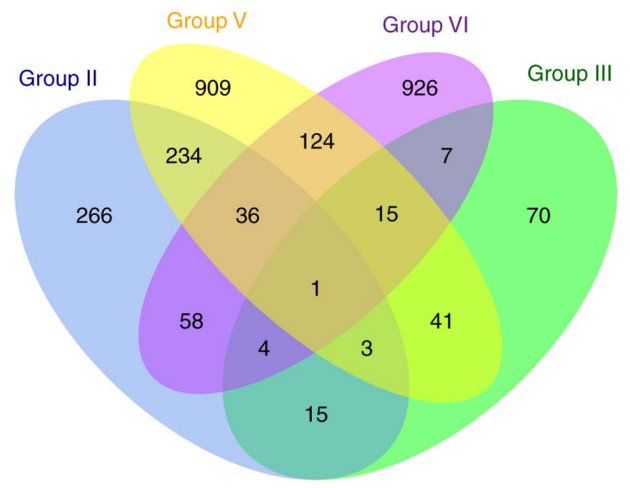

Figure 1. Venn diagram showing comprehensive analysis methods, which involves the comparison of different groups, of DEGs in the six groups. Group II: Gallbladder wall of gallbladder adenoma vs. gallbladder wall of gallbladder stones. Group III: Gallbladder wall of gallbladder cancer vs. gallbladder wall of gallbladder stones; Group IV: Gallbladder wall of gallbladder adenoma vs. gallbladder wall of cholesterol polyps; Group V: Gallbladder wall of gallbladder cancer vs. gallbladder wall of gallbladder adenoma. The DEGs in groups I and VI were not compared in this analysis. antigen, DP a1 chain (HLA-DPB1) forward, 5'-ATGACACTC TTCTGAATTGACTG-3' and reverse, 5'-GGTAATGATAAA ACATGCTCTC-3'; nuclear receptor subfamily 4 group A member 2 (NR4A2) forward, 5'-TCATCTCCTCAGACTGGG GG-3' and reverse, 5'-TGTACCAAATGCCCCTGTCC-3'; ephrin-B2 (EFNB2) forward, 5'-TATGCAGAACTGCGA TTTCCAA-3' and reverse, 5'-TGGGTATAGTACCAGTCC TTGTC-3'; four and a half LIM domains protein 1 forward (FHL1), 5'-AAATGCACAAAGTGTGCCCG-3' and reverse, 5'-TCGTTTGGGACACTCAGCAC-3'; insulin-like growth factor-binding protein 7 (IGFBP7) forward, 5'-ACAGTGGTT GATGCCTTAC-3' and reverse, 5'-CCCTTATGGGTTGCT AACTAC-3'; Rho Family GTPase (RND) forward, 5'-CTA TGACCAGGGGGCAAATA-3' and reverse, 5'-TCTTCGCTT TGTCCTTTCGT-3'; E3 ubiquitin-protein ligase NEURL1B (NEURL1B) forward, 5'-ACAGCAGCTTCCAAGACACA-3' and reverse, 5'-GTTGGGCAGGCTGTAGTAGG-3'; and GAPDH forward, 5'-ACTCCCATTCTTCCACCTTTG-3' 
A

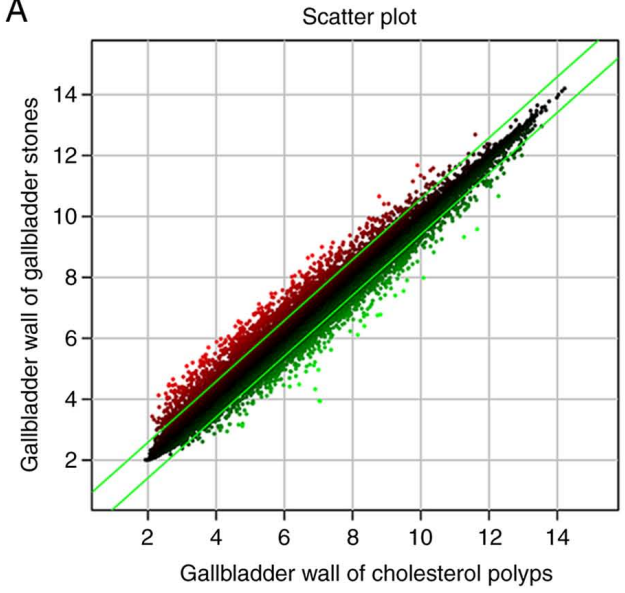

C

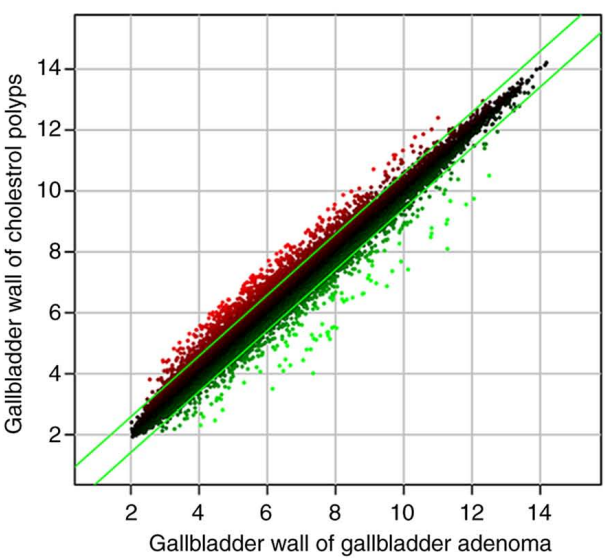

E

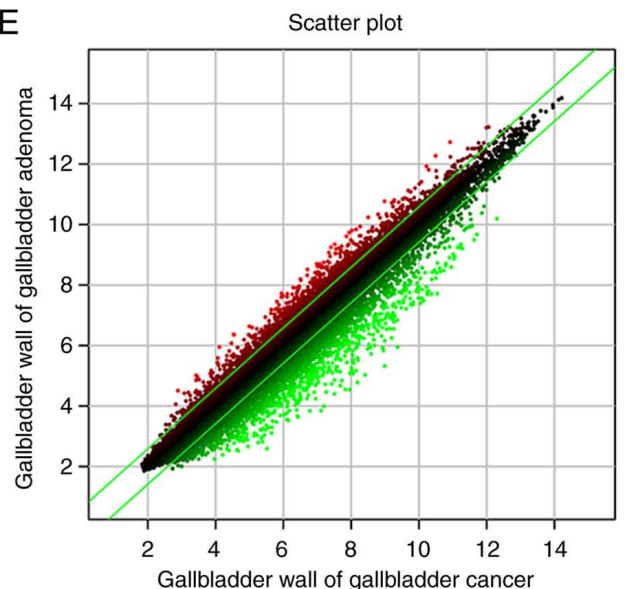

B

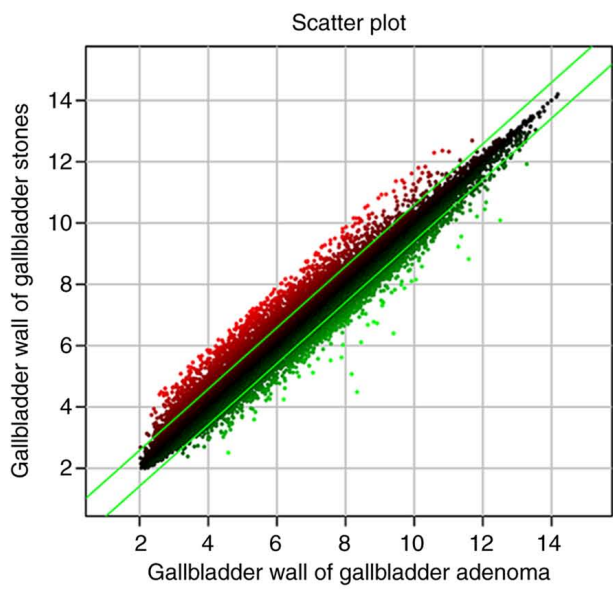

D

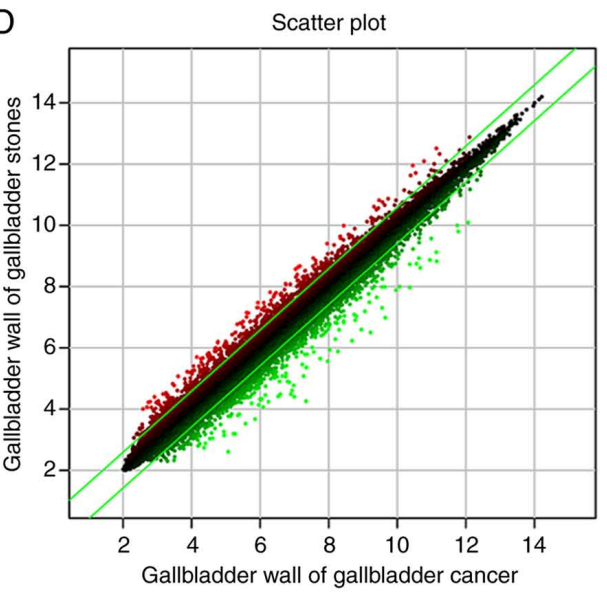

$\mathrm{F}$

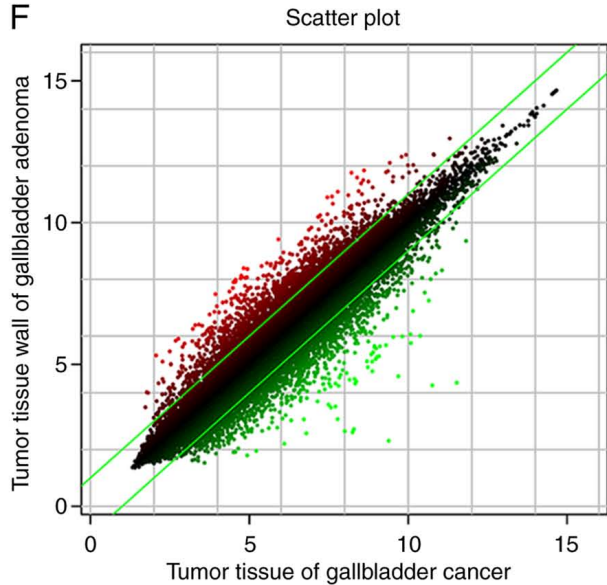

Figure 2. Scatter plots of genes in different compared groups. (A-F) Represent comparison I, II, III, IV, V and VI, respectively. Red represents upregulated genes and green represents downregulated genes. Comparison I: Gallbladder wall of gallstone vs. gallbladder wall of cholesterol polyps; Comparison II: Gallbladder wall of gallstone vs. gallbladder wall of gallbladder adenoma; Comparison III: Gallbladder wall of gallstone vs. gallbladder wall of gallbladder cancer; Comparison IV: Gallbladder wall of cholesterol polyps vs. gallbladder wall of gallbladder adenoma; Comparison V: Gallbladder wall of gallbladder adenoma vs. gallbladder wall of gallbladder cancer; Comparison VI: Tumor wall of gallbladder adenoma vs. tumor wall of gallbladder cancer.

and reverse, 5'-CCCTGTTGCTGTAGCCATATT-3'. GADPH served as an internal control. The relative expression levels were determined using the $2^{-\Delta \Delta \mathrm{Cq}}$ method (13).

Statistical analysis. All statistical analysis was conducted on R (14) or GraphPad Prism 7.0 (GraphPad Software, Inc.). Data were expressed as the mean $\pm \mathrm{SD}$. Each experiment was repeated at least three times. Comparisons between groups were analyzed by a Student's t-test. GO and KEGG annotation enrichment analyses were evaluated using a Fisher's exact test. For OS analysis, the samples were divided into high and low expression groups according to the median expression value of key genes. Differences between two groups were compared with Kaplan-Meier curves, followed by log-rank test. $\mathrm{P}<0.05$ was considered to indicate a statistically significant difference. 
A

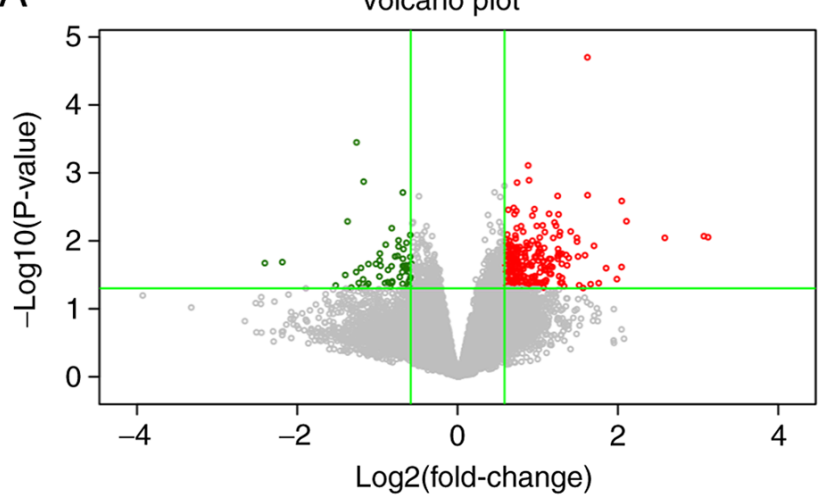

C

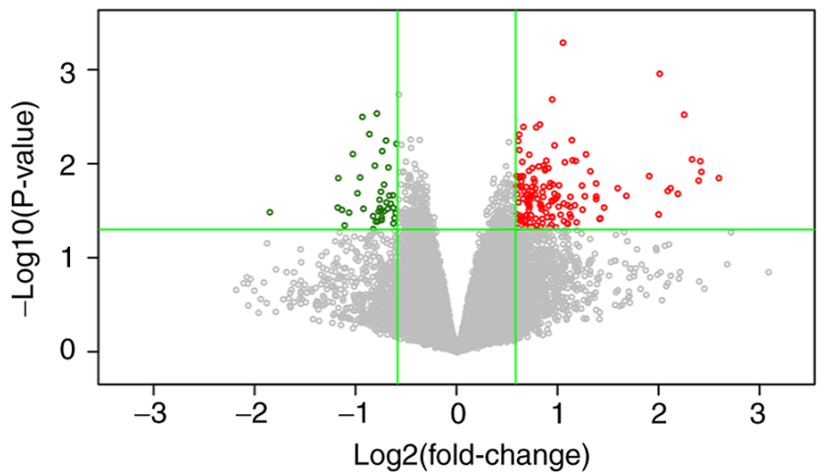

E

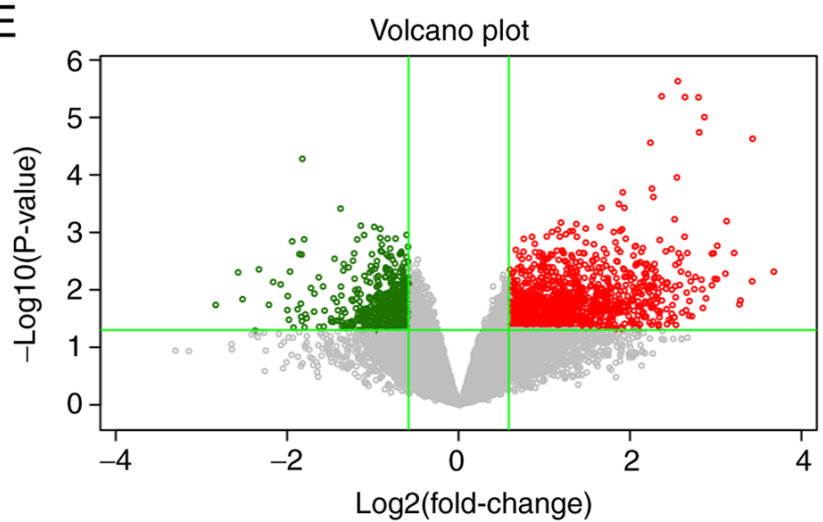

B

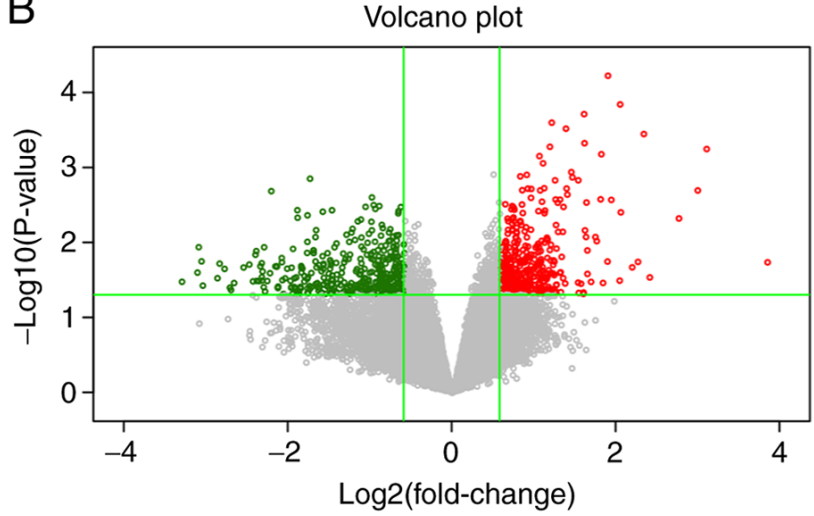

D

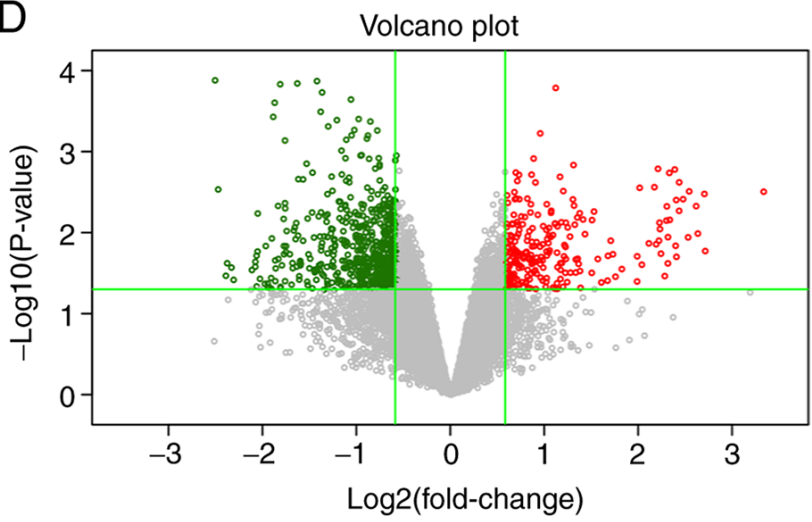

F

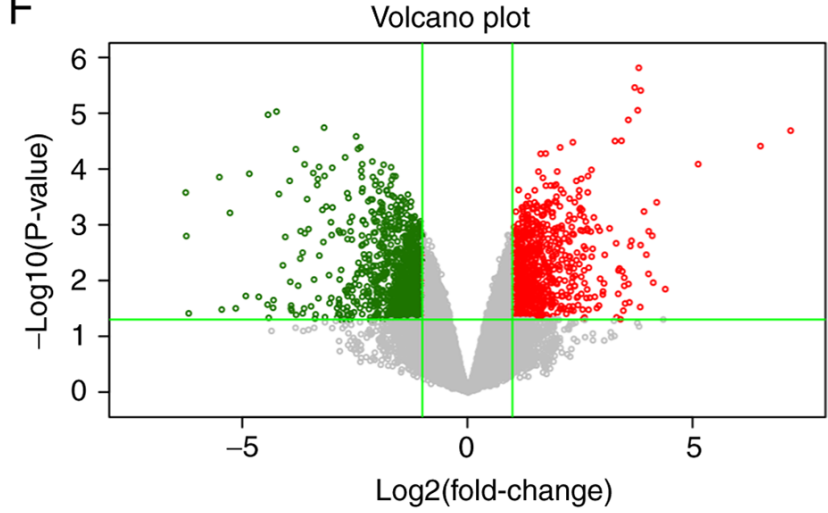

Figure 3. Volcano plots of compared groups. (A-F) Represent comparison I, II, III, IV, V and VI, respectively. Red represents upregulated genes and green represents downregulated genes. Comparison I: Gallbladder wall of gallstone vs. gallbladder wall of cholesterol polyps; Comparison II: Gallbladder wall of gallstone vs. gallbladder wall of gallbladder adenoma; Comparison III: Gallbladder wall of gallstone vs. gallbladder wall of gallbladder cancer; Comparison IV: Gallbladder wall of cholesterol polyps vs. gallbladder wall of gallbladder adenoma; Comparison V: Gallbladder wall of gallbladder adenoma vs. gallbladder wall of gallbladder cancer; Comparison VI: Tumor wall of gallbladder adenoma vs. tumor wall of gallbladder cancer.

\section{Results}

Transcript analysis results. In the present study, the gene expression profiles in the compared groups were analyzed via microarray analysis. The differential expression analysis results were shown in Table III according to $\mid \mathrm{FCl}>1.5$ and $\mathrm{P}$-value $<0.05$. The DEGs were marked for further analysis (Tables SI-SVI listed all DEGs in the six compared groups). The scatter plots show the distribution of upregulated genes in the two groups (Fig. 2). The volcano plots were used to show the DEGs between different compared groups. In Fig. 3, the red and green dots represented DEGs with the criteria of $|\mathrm{FC}|>1.5$ and P-value $<0.05$, and the gray dot indicates genes with no significant difference.
Table III. Differentially expressed genes in six different comparative groups.

\begin{tabular}{lcc}
\hline $\begin{array}{l}\text { Comparative } \\
\text { groups }\end{array}$ & $\begin{array}{c}\text { Total number of } \\
\text { upregulated genes }\end{array}$ & $\begin{array}{c}\text { Total number of } \\
\text { downregulated genes }\end{array}$ \\
\hline I & 198 & 43 \\
II & 346 & 271 \\
III & 116 & 40 \\
IV & 182 & 502 \\
V & 830 & 533 \\
VI & 540 & 632 \\
\hline
\end{tabular}


Table IV. Common DEGs in the gallbladder wall of gallbladder cancer and gallbladder adenoma.

A, Upregulated genes

\begin{tabular}{llllll}
\hline $\begin{array}{l}\text { Entrez } \\
\text { accession no. }\end{array}$ & Gene symbol & \multicolumn{1}{c}{ Gene name } & Fold-change & $\begin{array}{c}\text { False } \\
\text { P-value }\end{array}$ \\
\hline 1906 & EDN1 & Endothelin 1 & 1.549618769 & 0.029390674 & 0.955609729 \\
83661 & MS4A8 & Membrane-spanning 4-domains, & 2.003454854 & 0.016940921 & 0.955609729 \\
& & subfamily A, member 8 & & \\
213 & ALB & Albumin & 2.246885592 & 0.044086126 & 0.955609729 \\
10232 & MSLN & Mesothelin & 3.577553479 & 0.034944882 & 0.955609729 \\
1515 & CTSV & Cathepsin V & 1.810360067 & 0.018438263 & 0.955609729 \\
573 & BAG1 & BCL2 associated athanogene 1 & 1.619984489 & 0.045294551 & 0.955609729 \\
100507412 & LOC100507412 & Uncharacterized LOC100507412 & 2.405560916 & 0.00588484 & 0.955609729 \\
55283 & MCOLN3 & Mucolipin 3 & 2.597985418 & 0.035436453 & 0.955609729 \\
7586 & ZKSCAN1 & Zinc finger with KRAB and & 2.303988209 & 0.010795501 & 0.955609729 \\
& & SCAN domains 1 & & & \\
\hline
\end{tabular}

B, Downregulated genes

\begin{tabular}{|c|c|c|c|c|c|}
\hline $\begin{array}{l}\text { Entrez } \\
\text { accession no. }\end{array}$ & Gene symbol & Gene name & Fold-change & P-value & $\begin{array}{c}\text { False } \\
\text { discovery rate }\end{array}$ \\
\hline 6926 & TBX3 & T-box 3 & -1.97381941 & 0.024886922 & 0.955609729 \\
\hline 25987 & TSKU & $\begin{array}{l}\text { Tsukushi, small leucine rich } \\
\text { proteoglycan }\end{array}$ & -1.506934454 & 0.049505143 & 0.955609729 \\
\hline 6319 & SCD & $\begin{array}{l}\text { Stearoyl-coa desaturase } \\
\text { (delta-9-desaturase) }\end{array}$ & -1.692411038 & 0.031149526 & 0.955609729 \\
\hline 4857 & NOVA1 & $\begin{array}{l}\text { Neuro-oncological ventral } \\
\text { antigen } 1\end{array}$ & -1.754139316 & 0.041834676 & 0.955609729 \\
\hline 5209 & PFKFB3 & $\begin{array}{l}\text { 6-phosphofructo-2-kinase/ } \\
\text { fructose-2,6-biphosphatase } 3\end{array}$ & -1.859592699 & 0.015450602 & 0.955609729 \\
\hline
\end{tabular}

To effectively distinguish DEGs in the different comparison groups, unsupervised hierarchical clustering analysis was performed. This analysis could distinguish between the different samples in the six comparison groups (Figs. S1-S6).

Comparative analysis. In comparison A (Groups I-III; Table II): i) A total of eight commonly upregulated genes [including Uncharacterized LOC101928168 (LOC101928168), 3-Hydroxy-3-Methylglutaryl-CoA Synthase 2 (HMGCS2), Secretagogin, EF-Hand Calcium Binding Protein (SCGN), Chimerin 2 (CHN2), X-Linked Kx Blood Group (XK), Mucin 6, Oligomeric Mucus/Gel-Forming (MUC6), Phospholipid Phosphatase 5 (PLPP5) and Heat Shock Protein Family H Member 1 (HSPH1)] and one downregulated gene [ST8 $\alpha$-N-Acetyl-Neuraminide $\alpha$-2,8-Sialyltransferase 4 (ST8SIA4)] were identified in cholesterol polyps, gallbladder adenoma and gallbladder cancer for gallbladder walls (data not shown); ii) A total of 14 common DEGs were found to overlap in the gallbladder wall of gallbladder cancer and gallbladder adenoma (Table IV); iii) A total of 273 differentially upregulated genes were only expressed in the gallbladder wall of gallbladder adenoma, of which the 20 most significantly
DEGs, according to the FC, were selected to continue further analysis (Tables IV and V). A total of 85 upregulated genes were identified in the gallbladder wall of gallbladder cancer (Table VI). The 20 most significantly DEGs were selected, as shown in Table VI.

In comparison B (Group IV; Table I), 684 DEGs in the gallbladder wall of gallbladder adenoma, of which 182 were upregulated and 502 were downregulated, shown in Table SIV. The top 20 DEGs are shown in Table VII. In comparison C, it was revealed that 177 DEGs were expressed both in the tumor tissue and gallbladder wall in gallbladder cancer. The 20 most significantly DEGs were selected according to the FC (Table VIII). In comparison D, 459 upregulated genes were found in the tumor of gallbladder cancer. The top 20 upregulated genes that were identified according to FC in Table IX.

Function enrichment analysis. To better understand the biological pathways that were affected in the gallbladder walls of cholesterol polyps, gallbladder adenoma and gallbladder cancer, GO analysis was conducted on the DEGs. Fig. 4A shows that the GO terms that experienced the most significant 
Table V. Top 20 upregulated genes in the gallbladder wall of gallbladder adenoma.

\begin{tabular}{|c|c|c|c|c|c|}
\hline $\begin{array}{l}\text { Entrez } \\
\text { accession no. }\end{array}$ & Gene symbol & Gene name & Fold-change & P-value & $\begin{array}{c}\text { False } \\
\text { discovery rate }\end{array}$ \\
\hline 3115 & HLA-DPB 1 & $\begin{array}{l}\text { Major histocompatibility complex, } \\
\text { class II, DP } \beta 1\end{array}$ & 14.39294587 & 0.018542717 & 0.95561 \\
\hline 10321 & CRISP3 & Cysteine-rich secretory protein 3 & 8.596046776 & 0.000569554 & 0.95561 \\
\hline 9153 & SLC28A2 & $\begin{array}{l}\text { Solute carrier family } 28 \text { (concentrative } \\
\text { nucleoside transporter), member } 2\end{array}$ & 7.972874721 & 0.002038587 & 0.95561 \\
\hline 1733 & DIO1 & Deiodinase, iodothyronine, type I & 4.13402372 & 0.000144984 & 0.95561 \\
\hline 2568 & GABRP & $\begin{array}{l}\gamma \text {-aminobutyric acid (GABA) } \\
\text { A receptor, pi }\end{array}$ & 4.11863611 & 0.032541353 & 0.95561 \\
\hline 6555 & SLC10A2 & $\begin{array}{l}\text { Solute carrier family } 10 \text { (sodium/bile } \\
\text { acid cotransporter), member } 2\end{array}$ & 3.729761379 & 5.99474E-05 & 0.95561 \\
\hline 6819 & SULT1C2 & Sulfotransferase family $1 \mathrm{C}$ member 2 & 3.716642697 & 0.018104673 & 0.95561 \\
\hline 4496 & MT1H & Metallothionein $1 \mathrm{H}$ & 3.527957872 & 0.000668336 & 0.95561 \\
\hline 4494 & MT1F & Metallothionein $1 \mathrm{~F}$ & 3.505661422 & 0.002675451 & 0.95561 \\
\hline 54346 & UNC93A & Unc-93 homolog A (C. Elegans) & 3.355156356 & 0.008516354 & 0.95561 \\
\hline 148523 & CIART & $\begin{array}{l}\text { Circadian associated repressor of } \\
\text { transcription }\end{array}$ & 3.136234278 & 0.026466979 & 0.95561 \\
\hline 388561 & ZNF761 & Zinc finger protein 761 & 3.111132847 & 0.002949854 & 0.95561 \\
\hline 100127888 & SLCO4A1-AS1 & SLCO4A1 antisense RNA 1 & 3.072422599 & 0.006932207 & 0.95561 \\
\hline 4495 & MT1G & Metallothionein $1 \mathrm{G}$ & 3.050121402 & 0.00019533 & 0.95561 \\
\hline 2069 & EREG & Epiregulin & 3.031503175 & 0.048716806 & 0.95561 \\
\hline 7364 & UGT2B7 & $\begin{array}{l}\text { UDP glucuronosyltransferase } 2 \text { family, } \\
\text { polypeptide B7 }\end{array}$ & 2.971195084 & 0.035730027 & 0.95561 \\
\hline 3821 & KLRC1 & $\begin{array}{l}\text { Killer cell lectin-like receptor } \\
\text { subfamily } \mathrm{C} \text {, member } 1\end{array}$ & 2.902803001 & 0.00149172 & 0.95561 \\
\hline 3822 & KLRC2 & $\begin{array}{l}\text { Killer cell lectin-like receptor } \\
\text { subfamily C, member } 2\end{array}$ & 2.902803001 & 0.00149172 & 0.95561 \\
\hline 10562 & OLFM4 & Olfactomedin 4 & 2.899525179 & 0.03455814 & 0.95561 \\
\hline 990 & CDC6 & Cell division cycle 6 & 2.763474564 & 0.001361724 & 0.95561 \\
\hline
\end{tabular}

enrichment of comparison A was the BP 'Immune system process', $\mathrm{MF}$ 'Integrin binding' and the $\mathrm{CC}$ 'Anchoring junction'. Fig. 4B shows that the DEGs of gallbladder walls in cholesterol polyps vs. gallbladder adenoma participate in a number of GO pathways, the number of DEGs with the highest count had roles in the BP 'Tissue development', the $\mathrm{CC}$ 'Cell junction' and the MF 'Receptor binding'. Fig. 4C demonstrates that the number of DEGs of the tumor tissues in cholesterol polyps compared with gallbladder adenoma had the highest count in the BP 'Positive regulation of gene expression', the $\mathrm{CC}$ 'Cytoskeleton' and the MF 'Enzyme binding'.

KEGG pathway enrichment analysis. The biological pathways that were enriched by DEGs were also analyzed with KEGG. Fig. 5A shows that the most significantly enriched pathways in the gallbladder walls of cholesterol polyps, gallbladder adenoma and gallbladder cancer compared with normal groups was 'cell adhesion molecules (CAMs)'. Fig. 5B shows that the most significantly enriched pathway with DEGs in the gallbladder walls of gallbladder adenoma vs. gallbladder cancer was 'Cell adhesion molecules (CAMs)'. Fig. 5C indicates that the most significantly enriched pathway in the tumor tissues of gallbladder adenoma vs. gallbladder cancer was the 'Systemic lupus erythematosus'.

Validation of key genes in gallbladder cancer. Among the top 20 DEGs in the gallbladder wall and tumor of gallbladder cancer, seven novel DEGs, including HLA-DPB1 (Fig. 6A), NR4A2 (Fig. 6B), EFNB2 (Fig. 6C), FHL1 (Fig. 6D), IGFBP7 (Fig. 6E), RND3 (Fig. 6F) and NEURL1B (Fig. 6G) for gallbladder cancer were validated using GEPIA. HLA-DPB1, EFNB2, IGFBP7 and NEURL1B had a significantly higher expression in gallbladder cancer tissues compared with normal tissues. The prognostic value of these DEGs were further analyzed. There was no significant difference between low HLA-DPB1 expression and prognosis of gallbladder cancer (Fig. 7A). The low expression of NR4A2 (Fig. 7B) indicated poorer OS for patients with gallbladder cancer. No significant difference was found between patients with low EFNB2 expression and those with high EFNB2 expression (Fig. 7C). Low FHL1 expression predicted significantly less favorable OS (Fig. 7D). There was no significant difference observed for different expression levels of IGFBP7 (Fig. 7E), RND3 (Fig. 7F) and NEURL1B 
Table VI. Top 20 upregulated genes in the gallbladder wall of gallbladder cancer.

\begin{tabular}{|c|c|c|c|c|c|}
\hline $\begin{array}{l}\text { Entrez } \\
\text { accession no. }\end{array}$ & Gene symbol & Gene name & Fold-change & P-value & $\begin{array}{l}\text { False } \\
\text { discovery rate }\end{array}$ \\
\hline 54474 & KRT20 & Keratin 20 , type I & 6.027529 & 0.014263 & 0.99994 \\
\hline 11075 & STMN2 & Stathmin 2 & 4.545556 & 0.021002 & 0.99994 \\
\hline 22943 & DKK1 & $\begin{array}{l}\text { Dickkopf WNT signaling pathway } \\
\text { inhibitor } 1\end{array}$ & 3.983841 & 0.034789 & 0.99994 \\
\hline 3790 & KCNS3 & $\begin{array}{l}\text { Potassium voltage-gated channel, } \\
\text { modifier subfamily S, member } 3\end{array}$ & 3.193245 & 0.022064 & 0.99994 \\
\hline 3606 & IL18 & Interleukin 18 & 2.740635 & 0.029388 & 0.99994 \\
\hline 8174 & MADCAM1 & $\begin{array}{l}\text { Mucosal vascular addressin cell adhesion } \\
\text { molecule } 1\end{array}$ & 2.657304 & 0.038834 & 0.99994 \\
\hline 1305 & COL13A1 & Collagen, type XIII, $\alpha 1$ & 2.593326 & 0.016279 & 0.99994 \\
\hline 7171 & TPM4 & Tropomyosin 4 & 2.492788 & 0.012088 & 0.99994 \\
\hline 84189 & SLITRK6 & SLIT and NTRK like family member 6 & 2.419904 & 0.007957 & 0.99994 \\
\hline 79966 & SCD5 & Stearoyl-CoA desaturase 5 & 2.399926 & 0.02229 & 0.99994 \\
\hline 56892 & C8orf4 & Chromosome 8 open reading frame 4 & 2.363066 & 0.030948 & 0.99994 \\
\hline 81671 & VMP1 & Vacuole membrane protein 1 & 2.354891 & 0.017192 & 0.99994 \\
\hline 406991 & MIR21 & MicroRNA 21 & 2.354891 & 0.017192 & 0.99994 \\
\hline 55612 & FERMT1 & Fermitin family member 1 & 2.268497 & 0.042115 & 0.99994 \\
\hline 55816 & DOK5 & Docking protein 5 & 2.254499 & 0.009369 & 0.99994 \\
\hline 24147 & FJX1 & Four jointed box 1 & 2.241426 & 0.027788 & 0.99994 \\
\hline 2043 & EPHA4 & EPH receptor A4 & 2.181555 & 0.036922 & 0.99994 \\
\hline 1908 & EDN3 & Endothelin 3 & 2.174776 & 0.02892 & 0.99994 \\
\hline 1316 & KLF6 & Kruppel-like factor 6 & 2.17353 & 0.022611 & 0.99994 \\
\hline 440712 & C1orf186 & Chromosome 1 open reading frame 186 & 2.165575 & 0.034576 & 0.99994 \\
\hline 5318 & PKP2 & Plakophilin 2 & 2.134774 & 0.043853 & 0.99994 \\
\hline 63923 & TNN & Tenascin $\mathrm{N}$ & 2.081014 & 0.040874 & 0.99994 \\
\hline 78989 & COLEC11 & Collectin subfamily member 11 & 2.067131 & 0.000518 & 0.99994 \\
\hline 100131541 & LOC 100131541 & Uncharacterized LOC100131541 & 2.032802 & 0.035034 & 0.99994 \\
\hline 5727 & PTCH1 & Patched 1 & 2.01107 & 0.017085 & 0.99994 \\
\hline 1359 & CPA3 & Carboxypeptidase A3 (mast cell) & 1.992477 & 0.022002 & 0.99994 \\
\hline 3775 & KCNK1 & $\begin{array}{l}\text { Potassium channel, two pore domain } \\
\text { subfamily K, member } 1\end{array}$ & 1.975891 & 0.02328 & 0.99994 \\
\hline 5732 & PTGER2 & Prostaglandin E receptor 2 & 1.95077 & 0.006402 & 0.99994 \\
\hline 51751 & HIGD1B & $\begin{array}{l}\text { HIG1 hypoxia inducible domain family } \\
\text { member } 1 \mathrm{~B}\end{array}$ & 1.9257 & 0.025133 & 0.99994 \\
\hline 23705 & CADM1 & Cell adhesion molecule 1 & 1.907871 & 0.044745 & 0.99994 \\
\hline
\end{tabular}

(Fig. 7G). Therefore, the data presented here indicated that only NR4A2 and FHL1 could represent potential prognostic markers for patients with gallbladder cancer. Following validation using RT-qPCR, HLA-DPB1 (Fig. 8A), NR4A2 (Fig. 8B) and EFNB2 (Fig. 8C) had significantly higher expression levels in gallbladder cancer tissues compared with normal tissues. However, there was no statistical difference in FHL1 expression between gallbladder cancer tissues and normal tissues (Fig. 8D). Moreover, high IGFBP7 expression was determined in gallbladder cancer tissues compared with normal tissues (Fig. 8E). As shown in Fig. 8F, RND3 mRNA expression was significantly decreased in gallbladder cancer tissues compared with normal tissues. A significantly higher expression level of NEURL1B was also detected in gallbladder cancer tissues compared with normal tissues (Fig. 8G).

\section{Discussion}

Gallbladder disease is one of the most common causes of upper abdominal pain (15). It is critical to focus on gallbladder diseases due to the potential for malignant degeneration of any gallbladder lesion (15). Gallbladder adenomas and primary adenocarcinomas have been identified as the most common benign and malignant tumors, respectively (16). Nevertheless, efforts have been put into elucidating the pathophysiological mechanisms leading to the development of gallbladder cancer, however, most of these mechanisms remain unknown. 
Table VII. Top 20 upregulated genes in the gallbladder wall of gallbladder adenoma compared with the gallbladder wall of cholesterol polyps.

\begin{tabular}{|c|c|c|c|c|c|}
\hline $\begin{array}{l}\text { Entrez } \\
\text { accession no. }\end{array}$ & Gene symbol & Gene name & Fold-change & P-value & $\begin{array}{l}\text { False } \\
\text { discovery rate }\end{array}$ \\
\hline 8076 & MFAP5 & Microfibrillar associated protein 5 & 10.055828 & 0.00313194 & 0.930859211 \\
\hline 8483 & CILP & Cartilage intermediate layer protein & 5.7556811 & 0.01148426 & 0.930859211 \\
\hline 8839 & WISP2 & $\begin{array}{l}\text { WNT1 inducible signaling pathway } \\
\text { protein } 2\end{array}$ & 5.0126842 & 0.001836636 & 0.930859211 \\
\hline 4495 & MT1G & Metallothionein $1 \mathrm{G}$ & 4.958911 & 0.024060491 & 0.930859211 \\
\hline 4496 & MT1H & Metallothionein $1 \mathrm{H}$ & 4.7119253 & 0.018260689 & 0.930859211 \\
\hline 2202 & EFEMP1 & $\begin{array}{l}\text { EGF containing fibulin-like } \\
\text { extracellular matrix protein } 1\end{array}$ & 3.9536176 & 0.019679555 & 0.930859211 \\
\hline 7364 & UGT2B7 & $\begin{array}{l}\text { UDP glucuronosyltransferase } 2 \text { family, } \\
\text { polypeptide B } 7\end{array}$ & 3.9512615 & 0.040165838 & 0.930859211 \\
\hline 3489 & IGFBP6 & $\begin{array}{l}\text { Insulin like growth factor binding } \\
\text { protein } 6\end{array}$ & 3.3672636 & 0.035074166 & 0.930859211 \\
\hline 10562 & OLFM4 & Olfactomedin 4 & 3.3045794 & 0.018570013 & 0.930859211 \\
\hline 4494 & MT1F & Metallothionein $1 \mathrm{~F}$ & 3.2510145 & 0.01264233 & 0.930859211 \\
\hline 64167 & ERAP2 & Endoplasmic reticulum aminopeptidase 2 & 3.1751689 & 0.039260457 & 0.930859211 \\
\hline 1543 & CYP1A1 & $\begin{array}{l}\text { Cytochrome P450, family } 1 \text {, subfamily } \\
\text { A, polypeptide } 1\end{array}$ & 3.0349092 & 0.041312515 & 0.930859211 \\
\hline 388561 & ZNF761 & Zinc finger protein 761 & 2.8743053 & 0.00550548 & 0.930859211 \\
\hline 683 & BST1 & Bone marrow stromal cell antigen 1 & 2.8327043 & 0.00702193 & 0.930859211 \\
\hline 55057 & AIM1L & Absent in melanoma 1-like & 2.8267351 & 0.031481094 & 0.930859211 \\
\hline 100127888 & SLCO4A1-AS1 & SLCO4A1 antisense RNA 1 & 2.689454 & 0.01048406 & 0.930859211 \\
\hline 30835 & CD209 & CD209 molecule & 2.6028341 & 0.048163532 & 0.930859211 \\
\hline 148523 & CIART & $\begin{array}{l}\text { Circadian associated repressor of } \\
\text { transcription }\end{array}$ & 2.5922233 & 0.029837355 & 0.930859211 \\
\hline 10720 & UGT2B11 & $\begin{array}{l}\text { UDP glucuronosyltransferase } 2 \text { family, } \\
\text { polypeptide B11 }\end{array}$ & 2.5871195 & 0.005778714 & 0.930859211 \\
\hline 2199 & FBLN2 & Fibulin 2 & 2.5660098 & 0.024397318 & 0.930859211 \\
\hline
\end{tabular}

Therefore, it is crucial to disclose the molecular mechanisms of gallbladder cancer to promote the development of new cancer biomarkers and appropriate treatment strategies.

Different from other microarray studies, in the present study, the microarrays were comprehensively analyzed (17-19). Firstly, eight differentially expressed upregulated genes were found, which included LOC101928168, HMGCS2, SCGN, CHN2, XK, MUC6, PLPP5 and HSPH1 both in cholesterol polyps and gallbladder adenoma from gallbladder walls. Secondly, 14 common DEGs were identified in the gallbladder walls of gallbladder cancer and gallbladder adenoma. It is important to distinguish benign and malignant gallbladder adenoma due to the poor diagnosis of gallbladder cancer. T-Box Transcription Factor 3, Tsukushi, Small Leucine Rich Proteoglycan, Stearoyl-CoA Desaturase (SCD), NOVA Alternative Splicing Regulator 1 and 6-Phosphofructo-2-Kinase/Fructose-2,6-Biphosphatase 3 were downregulated in the gallbladder wall of gallbladder cancer and gallbladder adenoma; EDN1, MS4A8, ALB, MSLN, CTSV, BAG1, LOC100507412, MCOLN3 and ZKSCAN1 were upregulated in the gallbladder wall of gallbladder cancer and gallbladder adenoma. Thirdly, 273 upregulated genes were expressed in the gallbladder wall of gallbladder adenoma. Fourthly, the 20 most significantly DEGs that were upregulated in the gallbladder wall of gallbladder cancer were identified including KRT20, STMN2, DKK1, KCNS3, IL18, MADCAM1, COL13A1, TPM4, SLITRK6, SCD5, C8orf4, VMP1, MIR21, FERMT1, DOK5, FJX1, EPHA4, EDN3, KLF6 and C1orf186. Among them, DKK1 is known to regulate tumor angiogenesis, which is essential for tumor invasive growth and metastasis (20). IL18 has been reported to be a candidate cytokine that may provide a new insight into the development of next generation cancer immunotherapy (21). Desaturated fatty acids are essential for tumor cell survival, and SCD5 may represent a viable target for the development of novel agents for cancer treatment (22), which could become a candidate for the treatment of gallbladder cancer. KLF6 is a member of the Kruppel-like family of zinc finger transcription factors, which has been identified as a mutated tumor inhibitor in selective human cancer types, but not gallbladder cancer (23).

A total of 182 upregulated DEGs in the gallbladder walls of gallbladder adenoma were obtained and compared with that of cholesterol polyps. The top 20 most significantly expressed genes included MFAP5, CILP, WISP2, MT1G, 
Table VIII. Top 20 upregulated genes both in the tumor and gallbladder wall in gallbladder cancer.

\begin{tabular}{|c|c|c|c|c|c|}
\hline $\begin{array}{l}\text { Entrez } \\
\text { accession no. }\end{array}$ & $\begin{array}{l}\text { Gene } \\
\text { symbol }\end{array}$ & Gene name & Fold-change & P-value & $\begin{array}{c}\text { False } \\
\text { discovery rate }\end{array}$ \\
\hline 1490 & CTGF & Connective tissue growth factor & 12.721 & 0.0049 & 0.663 \\
\hline 3115 & HLA-DPB1 & $\begin{array}{l}\text { Major histocompatibility complex, class II, } \\
\text { DP } \beta 1\end{array}$ & 8.0389 & 0.0066 & 0.663 \\
\hline 3400 & ID4 & $\begin{array}{l}\text { Inhibitor of DNA binding } 4 \text {, dominant } \\
\text { negative helix-loop-helix protein }\end{array}$ & 6.919 & $4 \mathrm{E}-06$ & 0.044 \\
\hline 3399 & ID3 & $\begin{array}{l}\text { Inhibitor of DNA binding } 3 \text {, dominant negative } \\
\text { helix-loop-helix protein }\end{array}$ & 5.8099 & 0.0001 & 0.435 \\
\hline 1282 & COL4A1 & Collagen, type IV, $\alpha 1$ & 5.3601 & 0.0398 & 0.663 \\
\hline 4929 & NR4A2 & Nuclear receptor subfamily 4 group A member 2 & 5.0011 & 0.0113 & 0.663 \\
\hline 2669 & GEM & $\begin{array}{l}\text { GTP binding protein overexpressed in skeletal } \\
\text { muscle }\end{array}$ & 4.6392 & 0.0094 & 0.663 \\
\hline 1948 & EFNB2 & Ephrin-B2 & 4.5216 & 0.0087 & 0.663 \\
\hline 3397 & ID1 & $\begin{array}{l}\text { Inhibitor of DNA binding 1, dominant negative } \\
\text { helix-loop-helix protein }\end{array}$ & 4.3673 & 0.0121 & 0.663 \\
\hline 2919 & CXCL1 & $\begin{array}{l}\text { Chemokine (C-X-C motif) ligand } 1 \text { (melanoma } \\
\text { growth stimulating activity, } \alpha \text { ) }\end{array}$ & 4.2191 & 0.0453 & 0.663 \\
\hline 390 & RND3 & Rho family GTPase 3 & 4.1688 & 0.0017 & 0.663 \\
\hline 2273 & FHL1 & Four and a half LIM domains 1 & 4.1366 & 0.011 & 0.663 \\
\hline 3490 & IGFBP7 & Insulin like growth factor binding protein 7 & 4.1039 & 0.0369 & 0.663 \\
\hline 54492 & NEURL1B & Neuralized E3 ubiquitin protein ligase 1B & 3.8487 & 0.0083 & 0.663 \\
\hline 301 & ANXA1 & Annexin A1 & 3.811 & 0.0242 & 0.663 \\
\hline 10631 & POSTN & Periostin, osteoblast specific factor & 3.7339 & 0.0224 & 0.663 \\
\hline 79772 & MCTP1 & Multiple $\mathrm{C} 2$ domains, transmembrane 1 & 3.6779 & 0.0247 & 0.663 \\
\hline 3486 & IGFBP3 & Insulin like growth factor binding protein 3 & 3.4581 & 0.0304 & 0.663 \\
\hline 5327 & PLAT & Plasminogen activator, tissue & 3.288 & 0.0023 & 0.663 \\
\hline 26353 & HSPB 8 & Heat shock protein family B (small) member 8 & 3.2012 & 0.0416 & 0.663 \\
\hline
\end{tabular}

MT1H, EFEMP1, UGT2B7, IGFBP6, OLFM4, MT1F, ERAP2, CYP1A1, ZNF761, BST1, AIM1L, SLCO4A1-AS1, CD209, CIART, UGT2B11 and FBLN2. The overexpression of CCN5/WISP2 in adipose tissue has previously been secreted and circulated in the blood in a transgenic mouse model, which suggests that WISP2 could become a biomarker in blood for gallbladder adenoma and cholesterol polyps (24). The gene expression of MT1G, MT1H and MT1F in human peripheral blood lymphocytes can be used as potential biomarkers for cadmium exposure (25). Cadmium exposure could contribute to the development of gallbladder cancer (26). EFEMP1 expression accumulates angiogenesis and accelerates the growth of cervical cancer in vivo (27). Patients with UGT2B7*1/*2 genotypes, UGT2B7 genetic variation are at risk for suboptimal immune recovery due to significant long-term autologous induction (28). The expression of IGFBP-6 in vascular endothelial cells is upregulated by hypoxia and IGFBP-6 suppresses angiogenesis in vitro and in vivo (29), but this has not been reported in the context of gallbladder cancer. OLFM4 expression is associated with cancer differentiation, stage, metastasis and prognosis in a variety of cancer types, such as breast cancer, esophageal adenocarcinoma and gastrointestinal cancer, suggesting that it has underlying clinical value as an early cancer biomarker or therapeutic target (30). CYP1A1/1A2 isoenzymes are involved in EROD activity in blood lymphocytes (31); however, there is currently no previous report on the functions of this gene in gallbladder cancer. The production of extracellular cADPR, catalyzed by BST-1, followed by concentrating the uptake of cyclic nucleotides by hemopoietic progenitors, may be physiologically relevant in normal hematopoiesis (32), but its function in gallbladder cancer remains unknown. CD209 has been identified to present on monocyte-derived DCs, a cell adjuvant for cancer immunotherapy (33). FBLN2 is a novel gene associated with hypertension (34).

The top 20 upregulated genes were expressed both in tumors and gallbladder walls of gallbladder cancer, which included CTGF, HLA-DPB1, ID3, ID4, COL4A1, NR4A2, GEM, EFNB2, ID1, CXCL1, RND3, FHL1, IGFBP7, NEURL1B, ANXA1, POSTN, MCTP1, IGFBP3, PLAT and HSPB8. The study focused on whether these genes expression levels could be assessed using blood or bile. CTGF could play an important role in the inflammation of gallbladder cancer (35). Therefore, CTGF has the potential to become a future biomarker for gallbladder cancer, circulating in the blood and bile. It has been revealed that the dynamic changes of growth centers and plasma cell differentiation are determined by ID3 and E protein activity (35). Following validation 
Table IX. Top 20 upregulated genes in the tumor of gallbladder cancer.

\begin{tabular}{|c|c|c|c|c|c|}
\hline $\begin{array}{l}\text { Entrez } \\
\text { accession no. }\end{array}$ & $\begin{array}{c}\text { Gene } \\
\text { symbol }\end{array}$ & Gene name & Fold-change & P-value & $\begin{array}{l}\text { False } \\
\text { discovery rate }\end{array}$ \\
\hline 1048 & CEACAM5 & $\begin{array}{l}\text { Carcinoembryonic antigen-related cell } \\
\text { adhesion molecule } 5\end{array}$ & 143.4154524 & $2.06062 \times 10^{-5}$ & 0.0894515 \\
\hline 10562 & OLFM4 & Olfactomedin 4 & 90.22299879 & $3.89271 \times 10^{-5}$ & 0.0960529 \\
\hline 7020 & TFAP2A & $\begin{array}{l}\text { Transcription factor AP-2 } \alpha \text { (activating } \\
\text { enhancer binding protein } 2 \alpha \text { ) }\end{array}$ & 18.24994233 & $3.9829 \times 10^{-4}$ & 0.1609015 \\
\hline 1015 & CDH17 & Cadherin 17, LI cadherin (liver-intestine) & 16.14818371 & $1.31492 \times 10^{-3}$ & 0.1871078 \\
\hline 10451 & VAV3 & VAV guanine nucleotide exchange factor 3 & 16.0872594 & $7.651281 \times 10^{-3}$ & 0.2974407 \\
\hline 1604 & CD55 & $\begin{array}{l}\text { CD55 molecule, decay accelerating factor } \\
\text { for complement (Cromer blood group) }\end{array}$ & 14.25260113 & $3.93845 \times 10^{-6}$ & 0.0512905 \\
\hline 1373 & CPS1 & Carbamoyl-phosphate synthase 1 & 14.14519343 & $2.998467 \times 10^{-2}$ & 0.3979446 \\
\hline 3872 & KRT17 & Keratin 17, type I & 11.21846461 & $2.5881794 \times 10^{-2}$ & 0.3854011 \\
\hline 5268 & SERPINB5 & $\begin{array}{l}\text { Serpin peptidase inhibitor, clade B } \\
\text { (ovalbumin), member } 5\end{array}$ & 11.07304422 & $1.2500212 \times 10^{-2}$ & 0.3344667 \\
\hline 9843 & HEPH & Hephaestin & 11.07030706 & $8.947495 \times 10^{-3}$ & 0.3090802 \\
\hline 213 & ALB & Albumin & 10.91257754 & 0.034730042 & 0.408424 \\
\hline 3158 & HMGCS2 & $\begin{array}{l}\text { 3-hydroxy-3-methylglutaryl-CoA } \\
\text { synthase } 2 \text { (mitochondrial) }\end{array}$ & 10.74010853 & $6.900844 \times 10^{-3}$ & 0.2884597 \\
\hline 63928 & $\mathrm{CHP} 2$ & Calcineurin-like EF-hand protein 2 & 7.987754539 & $1.5774911 \times 10^{-2}$ & 0.3509474 \\
\hline 7031 & TFF1 & Trefoil factor 1 & 7.9601374 & 0.017823277 & 0.3616271 \\
\hline 11074 & TRIM31 & Tripartite motif containing 31 & 7.589614806 & $1.280721 \times 10^{-3}$ & 0.1871078 \\
\hline 23213 & SULF1 & Sulfatase 1 & 7.505284011 & $2.8219398 \times 10^{-2}$ & 0.3929094 \\
\hline 3216 & HOXB6 & Homeobox B6 & 7.355635549 & $1.101194 \times 10^{-3}$ & 0.1861479 \\
\hline 84419 & C15orf48 & Chromosome 15 open reading frame 48 & 7.266966891 & $3.1186816 \times 10^{-2}$ & 0.4004668 \\
\hline 2982 & GUCY1A3 & Guanylate cyclase 1 , soluble, $\alpha 3$ & 7.041356237 & $1.9708261 \times 10^{-2}$ & 0.3677601 \\
\hline 8329 & HIST1H2AI & Histone cluster 1, h2ai & 6.935644729 & $7.41761 \times 10^{-4}$ & 0.1737322 \\
\hline
\end{tabular}

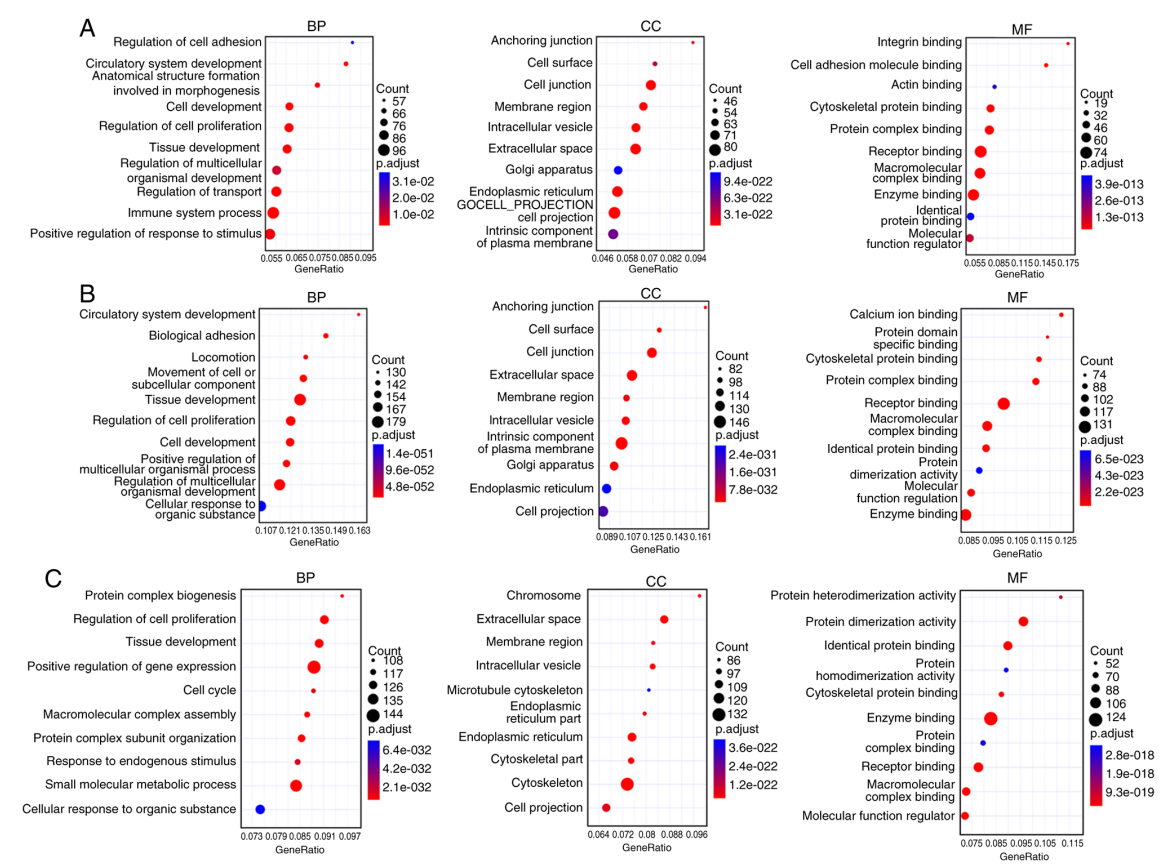

Figure 4. GO function enrichment analysis of all the compared groups. (A) GO function enrichment analysis of (A) comparison I, II, III and IV, (B) comparison V and (C) comparison VI. GO, Gene Ontology; BP, biological process; CC, cellular component; MF, molecular function. Red represents upregulated genes and green represents downregulated genes. Comparison I: Gallbladder wall of gallstone vs. gallbladder wall of cholesterol polyps; Comparison II: Gallbladder wall of gallstone vs. gallbladder wall of gallbladder adenoma; Comparison III: Gallbladder wall of gallstone vs. gallbladder wall of gallbladder cancer; Comparison IV: Gallbladder wall of cholesterol polyps vs. gallbladder wall of gallbladder adenoma; Comparison V: Gallbladder wall of gallbladder adenoma vs. gallbladder wall of gallbladder cancer; Comparison VI: Tumor wall of gallbladder adenoma vs. tumor wall of gallbladder cancer. 

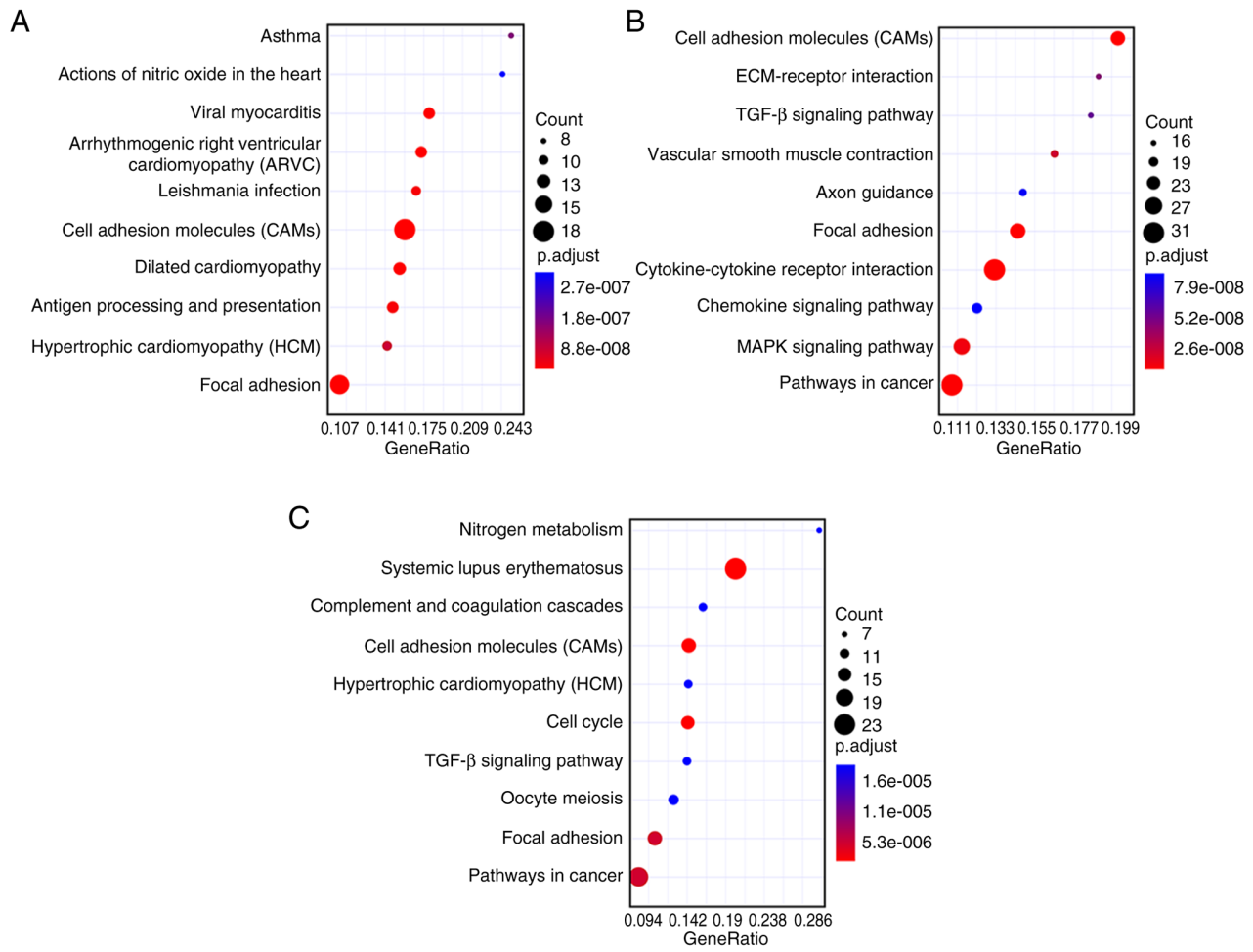

Figure 5. Top 10 pathways in KEGG pathway analysis of all compared groups. op 10 pathways in KEGG pathway analysis of (A) comparison I, II, III and IV, (B) comparison V and (C) comparison VI. KEGG, Kyoto Encyclopedia of Genes and Genomes; ECM, extracellular matrix; TGF, transforming growth factor. Comparison I: Gallbladder wall of gallstone vs. gallbladder wall of cholesterol polyps; Comparison II: Gallbladder wall of gallstone vs. gallbladder wall of gallbladder adenoma; Comparison III: Gallbladder wall of gallstone vs. gallbladder wall of gallbladder cancer; Comparison IV: Gallbladder wall of cholesterol polyps vs. gallbladder wall of gallbladder adenoma; Comparison V: Gallbladder wall of gallbladder adenoma vs. gallbladder wall of gallbladder cancer; Comparison VI: Tumor wall of gallbladder adenoma vs. tumor wall of gallbladder cancer.

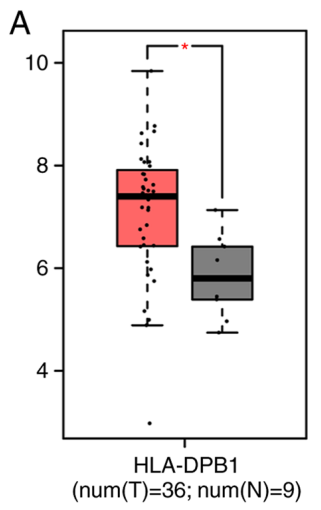

E

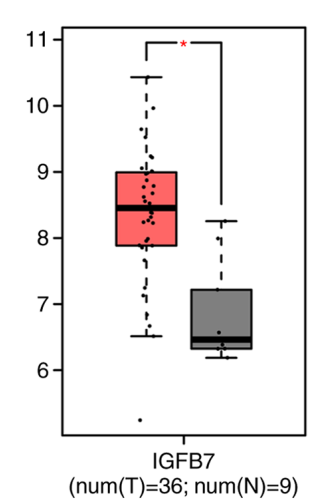

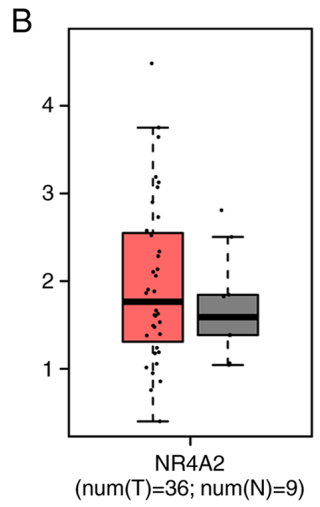

$\mathrm{F}$

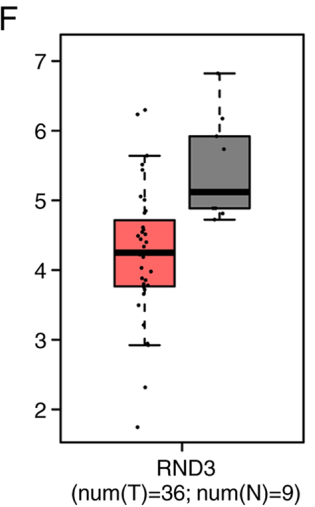

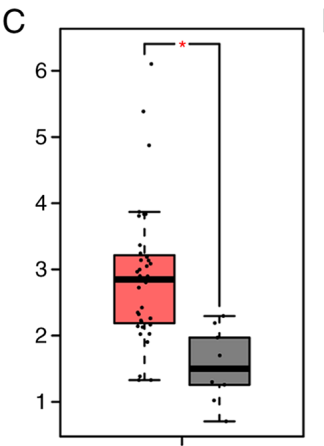

EFNB2 $(\operatorname{num}(\mathrm{T})=36 ; \operatorname{num}(\mathrm{N})=9)$

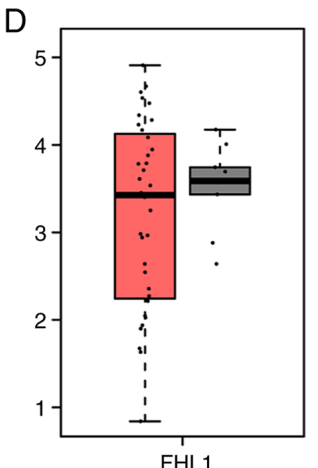

$(\operatorname{num}(\mathrm{T})=36 ; \operatorname{num}(\mathrm{N})=9)$

$\mathrm{G}$

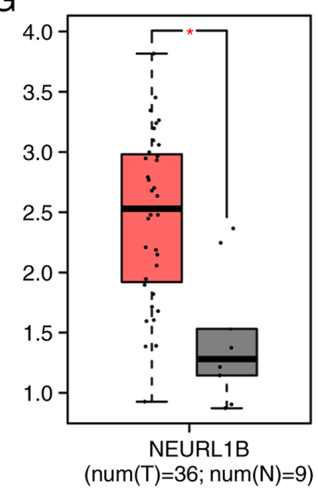

Figure 6. Validation of key genes in gallbladder cancer tissues using Gene Expression Profiling Interactive Analysis. (A) HLA-DPB1, (B) NR4A2, (C) EFNB2, (D) FHL1, (E) IGFBP7, (F) RND3 and (G) NEURL1B. HLA-DPB1, Major Histocompatibility Complex, Class II, DP $\beta 1$; NR4A2, nuclear receptor subfamily 4 group a member 2; EFNB2, ephrin B2; FHL1, four and a half LIM domains 1; IGFBP7, insulin like growth factor binding protein 7; RND3, Rho family GTPase 3; NEURL1B, neutralized E3 ubiquitin protein ligase 1B; T, tumor; $\mathrm{N}$, normal. " $\mathrm{P}<0.05$. 
A

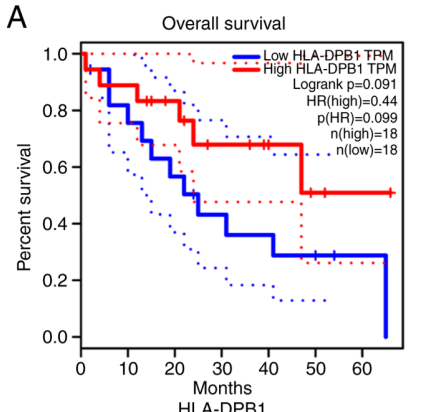

D

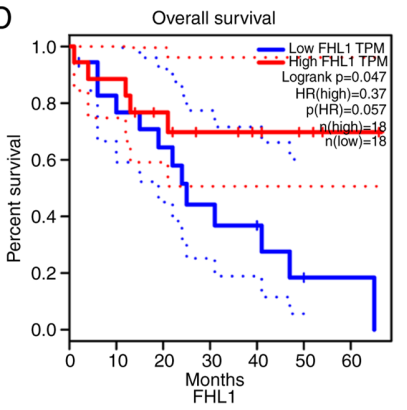

B

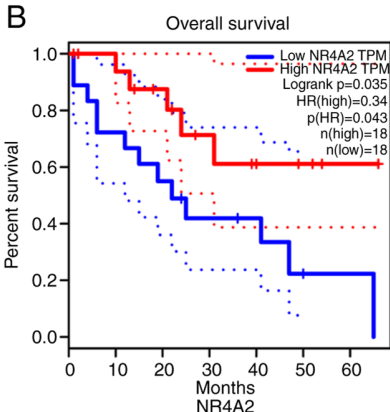

E

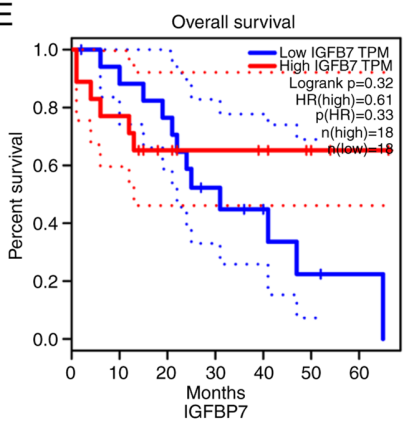

G

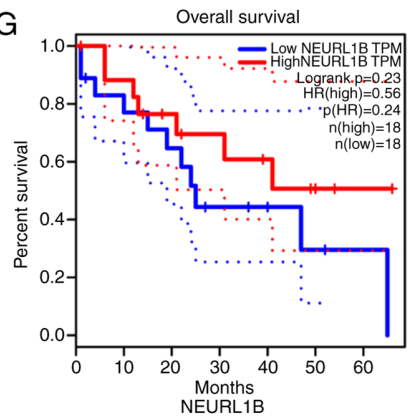

C

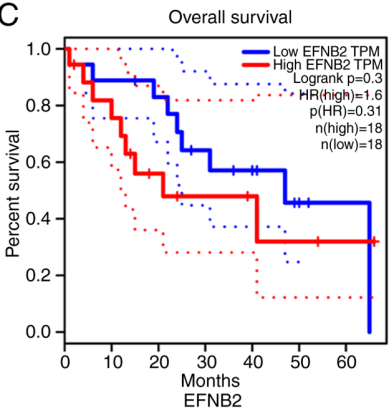

$\mathrm{F}$

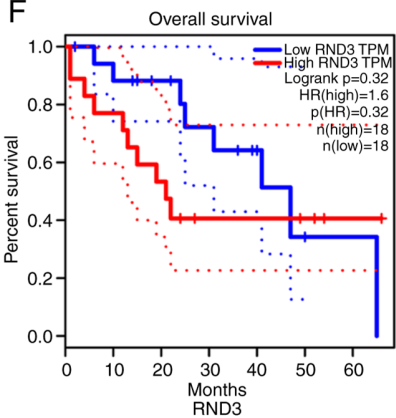

Figure 7. Overall survival analysis of key genes in gallbladder cancer. (A) HLA-DPB1, (B) NR4A2, (C) EFNB2, (D) FHL1, (E) IGFBP7, (F) RND3 and (G) NEURL1B. Red represents high expression and blue represents low expression. HLA-DPB1, Major Histocompatibility Complex, Class II, DP $\beta 1$; NR4A2, nuclear receptor subfamily 4 group a member 2; EFNB2, ephrin B2; FHL1, four and a half LIM domains 1; IGFBP7, insulin like growth factor binding protein 7; RND3, Rho family GTPase 3; NEURL1B, neutralized E3 ubiquitin protein ligase 1B; HR, hazard ratio.

A

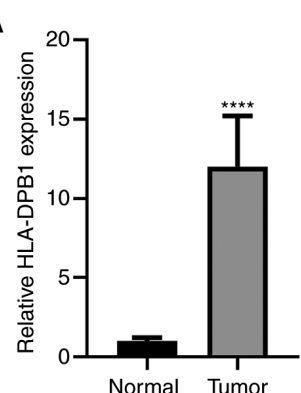

$E$

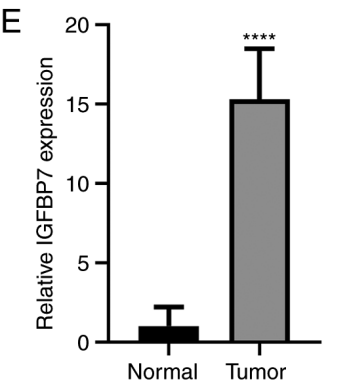

B

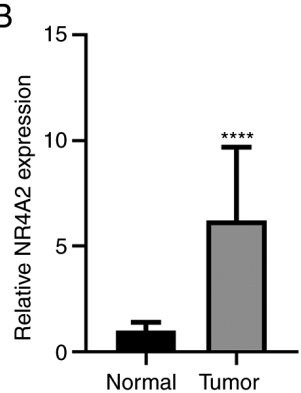

$\mathrm{F}$
C

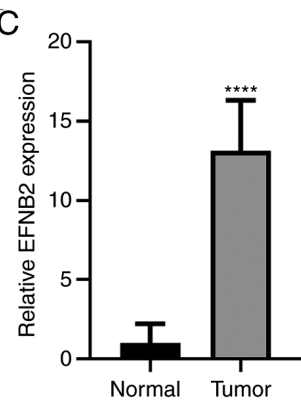

G

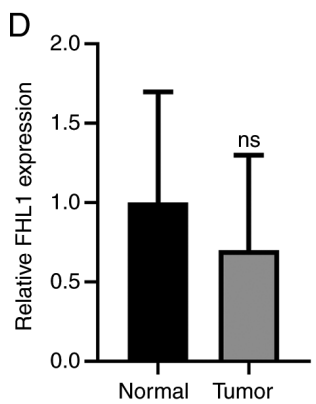

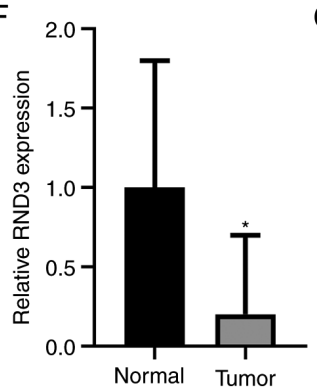

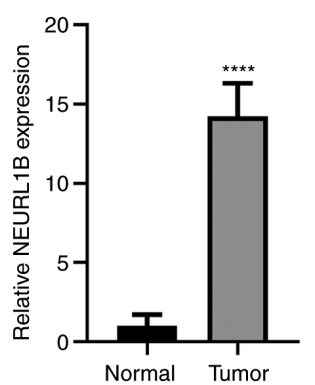

Figure 8. Validation of key genes in gallbladder cancer tissues using a reverse transcription-quantitative PCR assay. (A) HLA-DPB1, (B) NR4A2, (C) EFNB2, (D) FHL1, (E) IGFBP7, (F) RND3 and (G) NEURL1B. "P<0.05; and ${ }^{* * * * *}$ P $<0.0001$; ns, not significant; HLA-DPB1, Major Histocompatibility Complex, Class II, DP $\beta 1$; NR4A2, nuclear receptor subfamily 4 group a member 2; EFNB2, ephrin B2; FHL1, four and a half LIM domains 1; IGFBP7, insulin like growth factor binding protein 7; RND3, Rho family GTPase 3; NEURL1B, neutralized E3 ubiquitin protein ligase 1B. 
using RT-qPCR, the genes HLA-DPB1, NR4A2, EFNB2, IGFBP7 and NEURL1B were found to be highly expressed in gallbladder cancer. RND3 was significantly decreased in gallbladder cancer. HLA-DPB1, NR4A2 and FHL1 could be underlying prognostic markers for gallbladder cancer.

In the present study, a transcriptome profile was comprehensively analyzed enabling the identification of DEGs in gallbladder cancer, based on an annotation analysis of microarray studies. The present findings could provide a novel understanding on the tumorigenesis and development of gallbladder cancer.

\section{Acknowledgements}

Not applicable.

\section{Funding}

This work was funded by Natural Science Foundation of Liaoning Province (grant no. 2020-BS-283).

\section{Availability of data and materials}

The datasets used and/or analyzed during the current study are available from the corresponding author on reasonable request.

\section{Authors' contributions}

CG conceived and designed the study. XZ and XN conducted most of the experiments and data analysis and wrote the manuscript. BZ and LC participated in acquiring data and helped draft the manuscript. All authors read and approved the final manuscript.

\section{Ethics approval and consent to participate}

The present study was approved by the Ethics Committee of The First Affiliated Hospital of China Medical University (2018075). All patients who participated in the study signed written informed consent.

\section{Patient consent for publication}

Not applicable.

\section{Competing interests}

The authors declare that they have no competing interests.

\section{References}

1. Sicklick JK, Fanta PT, Shimabukuro K and Kurzrock R: Genomics of gallbladder cancer: The case for biomarker-driven clinical trial design. Cancer Metastasis Rev 35: 263-275, 2016.

2. Chandra V, Kim JJ, Mittal B and Rai R: MicroRNA aberrations: An emerging field for gallbladder cancer management. World $\mathbf{J}$ Gastroenterol 22: 1787-1799, 2016.

3. Kim YT, Kim J, Jang YH, Lee WJ, Ryu JK, Park YK, Kim SW, Kim WH, Yoon YB and Kim CY: Genetic alterations in gallbladder adenoma, dysplasia and carcinoma. Cancer Lett 169: 59-68, 2001.
4. Itoi T, Watanabe H, Ajioka Y, Oohashi Y, Takel K, Nishikura K, Nakamura Y, Horil A and Saito T: APC, K-ras codon 12 mutations and p53 gene expression in carcinoma and adenoma of the gall-bladder suggest two genetic pathways in gallbladder carcinogenesis. Pathol Int 46: 333-340, 1996.

5. Lee SH, Lee DS, You IY, Jeon WJ, Park SM, Youn SJ, Choi JW and Sung R: Histopathologic analysis of adenoma and adenoma-related lesions of the gallbladder. Korean J Gastroenterol 55: 119-126, 2010 (In Korean).

6. Liu MC, Jiang L, Hong HJ, Meng ZW, Du Q, Zhou LY, She FF and Chen YL: Serum vascular endothelial growth factors $C$ and $\mathrm{D}$ as forecast tools for patients with gallbladder carcinoma. Tumour Biol 36: 6305-6312, 2015.

7. Choi JH, Yun JW, Kim YS, Lee EA, Hwang ST, Cho YK, Kim HJ, Park JH, Park DI, Sohn CI, et al: Pre-operative predictive factors for gallbladder cholesterol polyps using conventional diagnostic imaging. World J Gastroenterol 14: 6831-6834, 2008.

8. Zhao MF, Huang P, Ge CL, Sun T, Ma ZG and Ye FF: Conjugated bile acids in gallbladder bile and serum as potential biomarkers for cholesterol polyps and adenomatous polyps. Int J Biol Markers 31: e73-e79, 2016.

9. Ritchie ME, Phipson B, Wu D, Hu Y, Law CW, Shi W and Smyth GK: limma powers differential expression analyses for RNA-sequencing and microarray studies. Nucleic Acids Res 43: e47, 2015.

10. Subramanian A, Tamayo P, Mootha VK, Mukherjee S, Ebert BL, Gillette MA, Paulovich A, Pomeroy SL, Golub TR, Lander ES and Mesirov JP: Gene set enrichment analysis: A knowledge-based approach for interpreting genome-wide expression profiles. Proc Natl Acad Sci USA 102: 15545-15550, 2005.

11. Kanehisa M, Goto S, Sato Y, Furumichi M and Tanabe M: KEGG for integration and interpretation of large-scale molecular data sets. Nucleic Acids Res 40 (Database Issue): D109-D114, 2012.

12. Tang Z, Li C, Kang B, Gao G, Li C and Zhang Z: GEPIA: A web server for cancer and normal gene expression profiling and interactive analyses. Nucleic Acids Res 45W: W98-W102, 2017.

13. Livak KJ and Schmittgen TD: Analysis of relative gene expression data using real-time quantitative PCR and the 2(-Delta Delta C(T)) method. Methods 25: 402-408, 2001.

14. R Core Team: R: A language and environment for statistical computing. R Foundation for Statistical Computing, Vienna, Austria, 2013. URL http://www.R-project.org/.

15. Rodriguez S, Gaunt TR, Guo Y, Zheng J, Barnes MR, Tang W, Danish F, Johnson A, Castillo BA, Li YR, et al: Lipids, obesity and gallbladder disease in women: Insights from genetic studies using the cardiovascular gene-centric 50K SNP array. Eur J Hum Genet 24: 106-112, 2016.

16. Mellnick VM, Menias CO, Sandrasegaran K, Hara AK, Kielar AZ, Brunt EM, Doyle MB, Dahiya N and Elsayes KM: Polypoid lesions of the gallbladder: Disease spectrum with pathologic correlation. Radiographics 5: 387-399, 2015.

17. Wang F, Wang R, Li Q, Qu X, Hao Y, Yang J, Zhao H, Wang Q, Li G, Zhang F, et al: A transcriptome profile in hepatocellular carcinomas based on integrated analysis of microarray studies. Diagn Pathol 12: 4, 2017.

18. Meng LZ, Fang JG, Sun JW, Yang F and Wei YX: Aberrant expression profile of long noncoding RNA in human sinonasal squamous cell carcinoma by microarray analysis. Biomed Res Int 2016: 1095710, 2016.

19. Liu L, Liu Y, Liu C, Zhang Z, Du Y and Zhao H: Analysis of gene expression profile identifies potential biomarkers for atherosclerosis. Mol Med Rep 14: 3052-3058, 2016.

20. Park H, Jung HY, Choi HJ, Kim DY, Yoo JY, Yun CO, Min JK, Kim YM and Kwon YG: Distinct roles of DKK1 and DKK2 in tumor angiogenesis. Angiogenesis 17: 221-234, 2014.

21. MaZ, Li W, Yoshiya S, Xu Y, Hata M, El-Darawish Y, Markova T, Yamanishi K, Yamanishi $\mathrm{H}$, Tahara $\mathrm{H}$, et al: Augmentation of immune checkpoint cancer immunotherapy with IL18. Clin Cancer Res 22: 2969-2980, 2016.

22. Roongta UV, Pabalan JG, Wang X, Ryseck RP, Fargnoli J, Henley BJ, Yang WP, Zhu J, Madireddi MT, Lawrence RM, et al: Cancer cell dependence on unsaturated fatty acids implicates stearoyl-CoA desaturase as a target for cancer therapy. Mol Cancer Res 9: 1551-1561, 2011.

23. Yin D, Komatsu N, Miller CW, Chumakov AM, Marschesky A, McKenna R, Black KL and Koeffler HP: KLF6: mutational analysis and effect on cancer cell proliferation. Int J Oncol 30: 65-72, 2007.

24. Grünberg JR, Elvin J, Paul A, Hedjazifar S, Hammarstedt A and Smith U: CCN5/WISP2 and metabolic diseases. J Cell Commun Signal 12: 309-318, 2018. 
25. Chang XL, Jin TY and Zhou YF: Metallothionein 1 isoform gene expression induced by cadmium in human peripheral blood lymphocytes. Biomed Environ Sci 19: 104-109, 2006.

26. Lee MH, Gao YT, Huang YH, McGee EE, Lam T, Wang B, Shen MC, Rashid A, Pfeiffer RM, Hsing AW and Koshiol J: A metallomic approach to assess associations of serum metal levels with gallstones and gallbladder cancer. Hepatology 71: 917-928, 2020.

27. En-lin S, Sheng-guo C and Hua-qiao W: The expression of EFEMP1 in cervical carcinoma and its relationship with prognosis. Gynecol Oncol 117: 417-422, 2010.

28. Habtewold A, Amogne W, Makonnen E, Yimer G, Riedel KD, Ueda N, Worku A, Haefeli WE, Lindquist L, Aderaye G, et al: Long-term effect of efavirenz autoinduction on plasma/peripheral blood mononuclear cell drug exposure and CD4 count is influenced by UGT2B7 and CYP2B6 genotypes among HIV patients. J Antimicrob Chemother 66: 2350-2361, 2011.

29. Zhang C, Lu L, Li Y, Wang X, Zhou J, Liu Y, Fu P, Gallicchio MA, Bach LA and Duan C: IGF binding protein-6 expression in vascular endothelial cells is induced by hypoxia and plays a negative role in tumor angiogenesis. Int J Cancer 130: 2003-2012, 2012.

30. Liu W and Rodgers GP: Olfactomedin 4 expression and functions in innate immunity, inflammation, and cancer. Cancer Metastasis Rev 35: 201-212, 2016.

31. Dey A, Parmar D, Dayal M, Dhawan A and Seth PK: Cytochrome P450 1A1 (CYP1A1) in blood lymphocytes evidence for catalytic activity and mRNA expression. Life Sci 69: 383-393, 2001.
32. Podestà M, Benvenuto F, Pitto A, Figari O, Bacigalupo A, Bruzzone S, Guida L, Franco L, Paleari L, Bodrato N, et al: Concentrative uptake of cyclic ADP-ribose generated by $\mathrm{BST}^{+} \mathrm{1}^{+}$stroma stimulates proliferation of human hematopoietic progenitors. J Biol Chem 280: 5343-5349, 2005.

33. Osugi Y, Vuckovic S and Hart DN: Myeloid blood CD11c(+) dendritic cells and monocyte-derived dendritic cells differ in their ability to stimulate T lymphocytes. Blood 100: 2858-2866, 2002.

34. Vallvé JC, Serra N, Zalba G, Fortuño A, Beloqui O, Ferre R, Ribalta $\mathbf{J}$ and Masana L: Two variants in the fibulin2 gene are associated with lower systolic blood pressure and decreased risk of hypertension. PLoS One 7: e43051, 2012.

35. Gloury R, Zotos D, Zuidscherwoude M, Masson F, Liao Y, Hasbold J, Corcoran LM, Hodgkin PD, Belz GT, Shi W, et al: Dynamic changes in Id3 and E-protein activity orchestrate germinal center and plasma cell development. J Exp Med 213: 1095-1111, 2016

(i) $($ This work is licensed under a Creative Commons Attribution-NonCommercial-NoDerivatives 4.0 International (CC BY-NC-ND 4.0) License. 